\title{
PRELIMINARY RESULTS OF REE-Y SORPTION ON CARBONATE ROCKS
}

\author{
Moraetis D. ${ }^{1,2}$ and Mouslopoulou V.,3 \\ ${ }^{1}$ Technical University of Crete, Department of Environmental Engineering moraetis@mred.tuc.gr \\ ${ }^{2}$ Technical University of Crete, Department of Mineral Resources Engineering \\ ${ }^{3}$ German Research Centre of Geosciences, GFZ, Potsdam, Germany,vasso@gfz-potsdam.de
}

\begin{abstract}
The Rare Earth Elements and Yttrium (REE-Y) have recently been proposed as good proxies for identifying rupture zones on carbonate fault scarps. Indeed, fluctuations in the REE-Y concentrations along a fault plane may be linked to the number and size of earthquakes that ruptured the fault. The enrichment is attributed to the contact of the soil with the carbonate fault scarp. Our study presents preliminary results from a series of experiments that aim to shed light on the mechanism associated with the REE-Y sorption on the limestone-soil interface. Rain simulation pot experiments, kinetic and isotherm batch experiments were employed to describe the mechanism of REE-Y sorption in calcite. Results reveal fast REE-Y sorption on the limestone surface after the simulation of five years of rainfall. The fast REE-Y sorption is also supported by the kinetic experiments. Isotherm tests show the higher affinity of calcite in the Light Rare Earth (LREE) compared to the Heavy Rare Earth Elements (HREE). The sorption of the REE in the form of carbonate complexes is proposed as a plausible mechanism of REE-Y incorporation into the limestone.
\end{abstract}

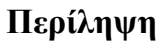

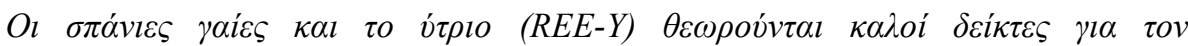

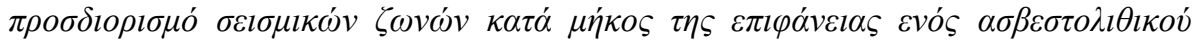

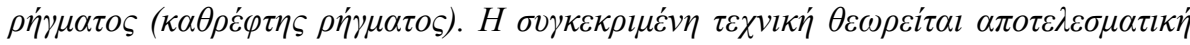

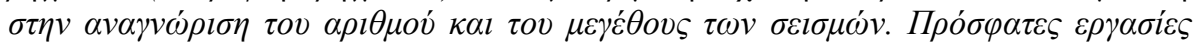

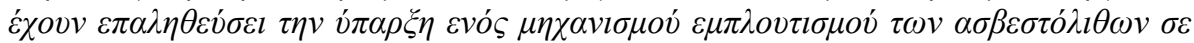

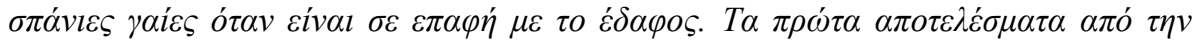

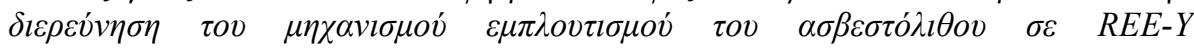

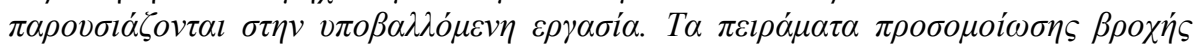

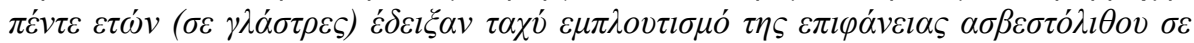

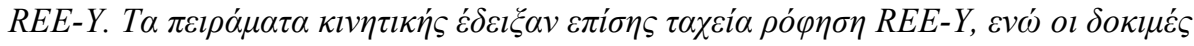

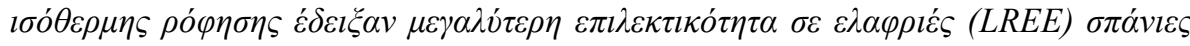

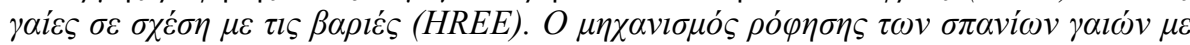

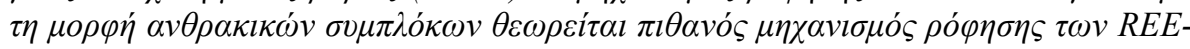
Y $\sigma \tau \eta v \varepsilon \pi \iota \varphi \alpha \dot{v \varepsilon \iota \iota \alpha} \tau \omega v \alpha \sigma \beta \varepsilon \sigma \tau \sigma \lambda i \theta \omega v$. 


\section{Introduction}

The Rare Earth Elements (REE) have been widely used as provenance indices either to describe the water hydrology or sediments origin (Dia et al., 2000; Roy et al., 2012). Furthermore soil processes, like argilluviation, carbonation etc., have been described through the REE fate and transport in soil horizons (Laveuf and Cornu, 2009). Other geological processes like biogeochemical conditions in paleo-seawater (Shields and Stille, 2001) and weathering processes have also used the REE as primary indices (Patino et al., 2003). The REE-Y concentration measured along the carbonate scarp of the Magnola Fault (Italy) revealed remarkable fluctuations that match with the rupture zones identified independently by $\mathrm{Cl}^{36}$ (Palumbo et al. 2004; Carcalliet et al., 2008). Manighetti at el. (2010) verified on the very same fault scarp that the REE-Y enrichment occurs due to the contact of the limestone with paleo-soils. Mouslopoulou et al. (2011) identified at least four zones of REE-Y enrichment on a fault of unknown earthquake history in Crete (the Spili Fault). The new proxies for the identification of paleo-earthquakes on carbonate faults are promising and the sound validation of the mechanism of REE enrichment on the limestone would enhance confidence that REE may be used prior to the costly method of $\mathrm{Cl}^{36}$ to constrain the slip history on carbonate faults.

Limestones have been proposed in various studies as adsorbents for heavy metals in the environment (Sdiri, 2012; Komnitsas et al., 2004; Godelitsas et al., 2003). The presence of carbonate minerals like calcite may have a direct or indirect effect in metal adsorption in limestones (Papadopoulos and Rowell, 1988). The direct effect is through their surface reactivity and the indirect is through their effect in the $\mathrm{pH}$ of reactive solutions. The metal incorporation in calcite can be a) with adsorption in the calcite surface through ion exchange with $\mathrm{Ca}$ or with complexation with carbonate groups bound in a disordered, hydrated surfaces (Zachara et al., 1988) and b) with precipitation (metal precipitates $\mathrm{MeCO}_{3}$ ) in solutions with high ionic strength metal solutions. The adsorption of metals in calcite showed to vary among different sorbates. For example, $\mathrm{Zn}$ appears to be adsorbed and rapidly desorbed (reverse reaction) whereas, $\mathrm{Mn}$ and $\mathrm{Cd}$ appear to be rapidly absorbed with very slow desorption rate (almost irreversible) (Papadopoulos and Rowell, 1988). $\mathrm{pH}$ changes in the presence of limestone is accompanied by carbonate $\left(\mathrm{CO}_{3}{ }^{2-}\right)$ release. REE shows high affinity of solution complexation with carbonates. The solubility of REE in most limestone aquifers is influenced partly by the solution complexation with carbonates and partly from the REE adsorption on charged surfaces like clays and oxides. It has been reported that Heavy Rare Earth Elements (HREE) are being more sorbed in clay surfaces compared to Light Rare Earth Elements (LREE). Moreover, the same has been observed in the Carrizo sand aquifer of Texas (Tang and Johannesson, 2005a). Thus, the calcite behaviour with respect to the metal adsorption is complex and the majority of the studies focus on the adsorption of the heavy metals and no data exist with respect to the REE-Y sorption in calcite.

In the case of REE-Y, little has been done to characterize the sorption processes on the interface between limestone and soil (Figure 1). To elucidate the mechanism responsible for the REE-Y enrichment we conducted a series of pot, kinetic and batch experiments.

\section{Materials and Methods}

The present study includes two experimental parts: a) the pot experiments with the placement of limestone bricks within pots which are filled with soil and b) the kinetic and isotherm sorption experiments. In the second part of experiments, the limestone was grinded in less than $250 \mu \mathrm{m}$. The grinded limestone for the kinetic and isotherm sorption experiment was aged by storing 0.5 limestone in $14 \mathrm{~L}$ of $0.02 \mathrm{~mol} / \mathrm{L} \mathrm{NaHCO}_{3}$. The aging process enhances the dissolution of small crystallites and crystallite with defects and the re-precipitation of uniform crystalline calcite, with less free energy in the surface. All kinetic and isotherm tests were performed with this aged limestone. $\mathrm{Ce}, \mathrm{Eu}$ and $\mathrm{Yb}$ were selected to represent Light, Medium and Heavy Rare Earth 


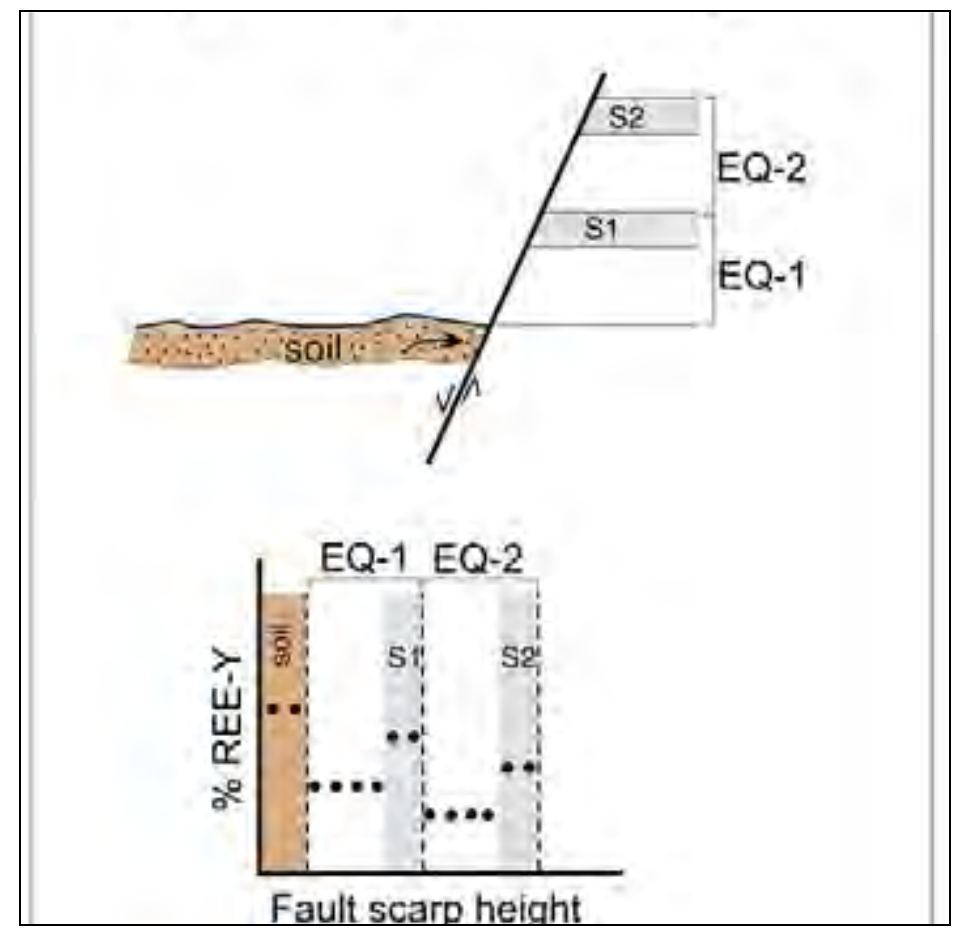

Figure 1 - Diagram illustrating the mechanism of REE-Y enrichment along a carbonate fault scarp. S1 and S2 represent paleo-ground levels which have been exhumed due to the successive earthquakes EQ1, EQ2. Modified from Mouslopoulou et al. (2011).

presented by Mouslopoulou et al. (2011). The oxidation states of each element was not considered in the present study and we calculate the bulk removal of $\mathrm{Ce}, \mathrm{Yb}, \mathrm{La}$ from each test (kinetic, isotherm etc.) The tests were performed in atmospheric $\mathrm{CO}_{2}\left(p \mathrm{CO}_{2}=3.2\right)$. The $\mathrm{Ce}$, Eu and $\mathrm{Yb}$ standards which were used for the solutions preparation (1000 ppm) were certi-pure in 2-3\% $\mathrm{HNO}_{3}$ from Merck Company.

\subsection{Pot Experiments}

Pot experiments were operated to simulate the limestone fault plane while buried under the ground surface (paleosoil-rock interaction). Thus, we removed orthogonal limestone segments from the fault plane (see Figure $2 \mathrm{a} \& \mathrm{~b}$ ) and covered the entire surface of the brick with waterproof silicon resin apart from the $2 / 3$ of the front surface (see Figure $2 \mathrm{c}$ ). The bricks were placed into pots (Figure 2d) and covered with soil which was sampled from the very colluvium wedge at the foot of the Spili Fault on Crete. The rain filtered through each pot was 4.2 litters per year of simulation according to the average rainfall in the area $(600 \mathrm{~mm})$ and normalised to the pot diameter $(6 \mathrm{~cm})$. A total of five years were simulated whereas in between simulations the pots were dried with natural aeration (average $30^{\circ}$ Celsius). Synthetic rain of specific ionic strength $\left(5.6^{*} 10^{-4} \mathrm{~mol} / \mathrm{L}\right)$ and $\mathrm{pH}$ (5.39) was used in pot experiments following the chemical analysis of rain from Samara et al. (1992). The salts that were used for synthetic rain comprised of $\mathrm{CaSO}_{4} \cdot 2 \mathrm{H}_{2} \mathrm{O}, \mathrm{KCl}$, $\mathrm{MgCl}_{2} .6 \mathrm{H}_{2} \mathrm{O}, \mathrm{NaNO}_{3}$, whereas $\mathrm{HCl}, \mathrm{H}_{2} \mathrm{SO}_{4}$ and $\mathrm{HNO}_{3}$ were used for $\mathrm{pH}$ adjustment. Tests were conducted at $25^{\circ} \mathrm{C}$ and $15^{\circ} \mathrm{C}$. All pot experiments were obtained in triplicates.

\subsection{Kinetic and Isotherm Tests}

Kinetic and isotherm tests were conducted in solid/solution ratio of $1 / 40$. The $\mathrm{pH}$ for both tests was 7.59. With the use of Mineql we calculate the composition of the solutions in equilibrium with calcite at this $\mathrm{pH}$. We applied the aqueous speciation reactions and equilibrium constants given by 
Zachara et al. (1988). The time intervals were $3 \mathrm{~h}, 6 \mathrm{~h}, 12 \mathrm{~h}, 1 \mathrm{~d}, 5 \mathrm{~d}, 7 \mathrm{~d}$ for the kinetic tests, hence the REE concentrations was $10^{-4} \mathrm{~mol} / \mathrm{L}$. The isotherm tests were conducted with the REE concentration of $10^{-3}, 10^{-4}, 10^{-5}, 10^{-6}, 10^{-7} \mathrm{~mol} / \mathrm{L}$ at $\mathrm{pH} 7.59$. After the addition of the REE standard the $\mathrm{pH}$ dropped in 5.6 in both kinetic and isotherm tests. We adjusted the $\mathrm{pH}$ at the isotherm test with the use of $\mathrm{NaOH}$, whereas the kinetic test was left to equilibrate without $\mathrm{pH}$ adjustment. The calcite equilibrium solution in both kinetic and isotherm experiments were prepared by mixing $\mathrm{HClO}_{4}, \mathrm{CaCl}_{2} \mathrm{O}_{8}, \mathrm{NaHCO}_{3}, \mathrm{NaOH}$.
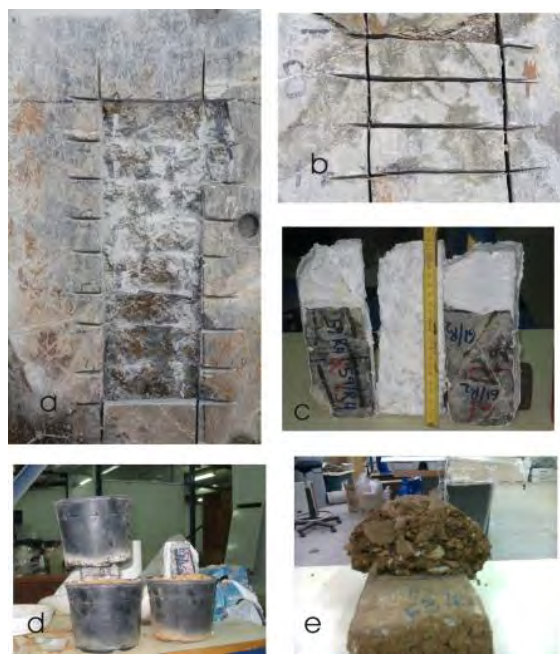

Figure 2 - (a) and (b) The bricks were detached from the carbonate fault plane by using electric saw; (c) waterproof silicon coverage of the brick; (d) brick placement into pots filled with soil; (e) brick removal after 5 years of rain simulation.

\section{Results}

\subsection{Pot Experiments}

The results of the pot experiments after simulating 5 years of rainfall at two different temperatures $\left(15^{\circ}\right.$ and $25^{\circ}$ Celsius) are illustrated in Figure 3 . The difference (\% change) in REE-Y concentration between the outer surfaces A1, B1 (which were in contact with the soil) on each

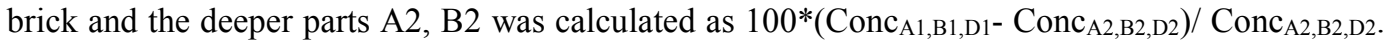
The Conc $\mathrm{Al}_{\mathrm{A} 1 \mathrm{~B} 1, \mathrm{D} 1}$ refers to the concentration in each of the A1, B1 or D1 segments whereas the Conc $_{\mathrm{A} 2, \mathrm{~B} 2, \mathrm{D} 2}$ refers to the concentration of the immediately deeper A2, B2 and D2 segments (as shown in Figure 3). At temperatures of $25^{\circ}$ Celsius, the average increase recorded in the A1 and B1 segments was $40 \%$ and $23 \%$, respectively. At temperatures of $15^{\circ}$ Celsius, the average increase recorded in the A1 and B1 segments was 36 and 5\%, respectively. In contrast, D1 segment shows lower REE-Y concentration compared to D2 segment (approximately $-45 \%$ for both tests temperatures; minus refers to decrease in concentration). The limestone at $15^{\circ}$ Celsius experiment showed generally lower enrichment in REE-Y compared to that recorded at $25^{\circ}$ Celsius (Figure 3).

\subsection{Kinetic and IsothermRresults}

The results from the isotherm sorption tests and the kinetic sorption tests are shown in Figure 4 . The limestone selectivity was higher for $\mathrm{Ce}$ compared to $\mathrm{Eu}$ and $\mathrm{Yb}$ and that remained stable for both tested temperatures. There was a slight increase in the limestone affinity for the REE in the temperature of $15^{\circ} \mathrm{C}$, especially for $\mathrm{Ce}$ and $\mathrm{Yb}$ as it is evident from the slope of the line. The linearity of the sorption isotherm, as depicted in the log-log diagram of Figure $4 a \& b$, resembles the isotherm of Freundlich. 

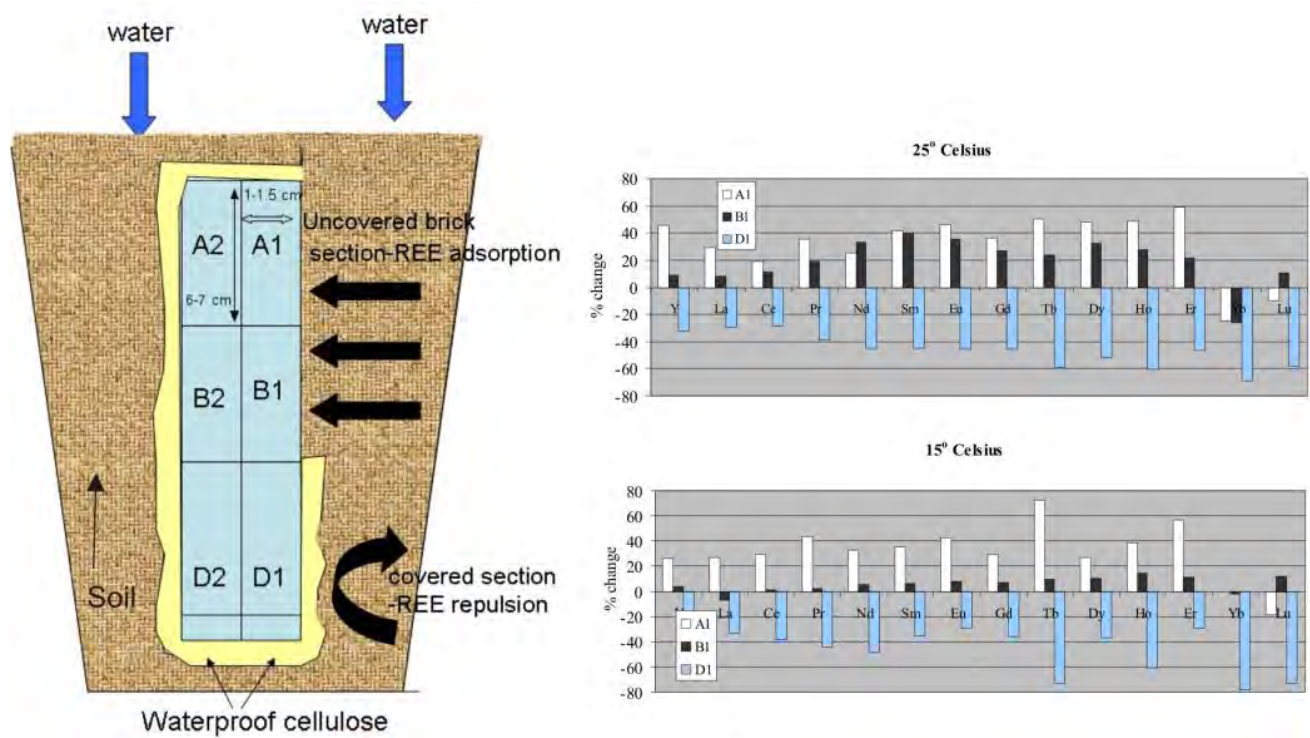

Figure 3 - Schematic diagram illustrating a pot experiment that involves a limestone brick buried within a soil. The results (in the two plots) derive by comparing the REE-Y concentration in $\mathrm{A} 1$ and $\mathrm{A} 2, \mathrm{~B} 1$ and $\mathrm{B} 2$ and $\mathrm{D} 1$ and $\mathrm{D} 2$ segments on each brick at two different temperatures $\left(15^{\circ}\right.$ and $25^{\circ}$ Celsius $)$.
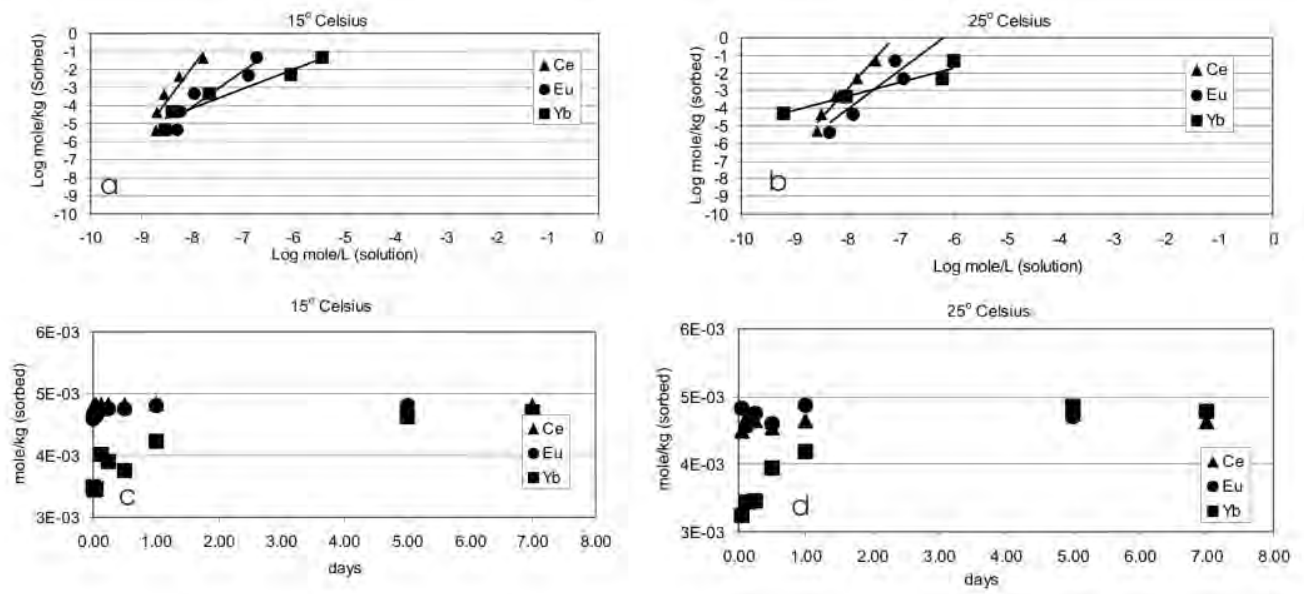

Fig

ure 4 - (a) and (b) Sorption isotherm tests for Ce, Eu and Yb at two different temperatures; (c) and (d) kinetic sorption tests for $\mathrm{Ce}, \mathrm{Eu}$ and $\mathrm{Yb}$ at two different temperatures.

The kinetic test shows immediate sorption for $\mathrm{Ce}$ and $\mathrm{Eu}$ and slower sorption for $\mathrm{Yb}$ (up to the $1^{\text {st }}$ day of the experiment). The three REE reached identical the same sorption level after the $1^{\text {st }}$ day. The kinetic test at the $7^{\text {th }}$ day shows a slight decrease in the sorption of all three REE. Thus, REE with high atomic number (e.g. Yb) show slower sorption in the $1^{\text {st }}$ day of the kinetic test compared to REE with lower atomic number $(\mathrm{Ce}, \mathrm{Eu})$.

\section{Discussion}

\subsection{Pot Experiments}

Preliminary results show that there is indeed a mechanism which is responsible for the recorded increase in the concentration of REE on the limestone, at localities where the latter is in direct 
contact with the soil. The REE enrichment on the buried surfaces A1 and B1 was clear, as was the non-enrichment of the D1 surface. The enrichment was achieved in pot-experiments after simulating five years of rainfall. Thus, two conceptual models may arise: a) the REE-Y escape from the soil through a soil solution and subsequently they are sorbed by the limestone surface b) the limestone surface is weathered due to its contact with acidic soil solution and the REE-Y, which were already in the limestone, dissolute and become subsequently re-sorbed (precipitate) in the limestone surface. The latter is thought to be impossible considered the level of \% percentage change in the REE-Y concentration and the short duration of the experiment. It would require extreme dissolution of the limestone surface to change the REE-Y content at a depth of $1.5 \mathrm{~cm}$ (Figure 3). Thus, the plausible scenario is the one that supports the origin of the REE-Y from the soil.

The measurements of the chemical parameters in the infiltrates from the pot experiments revealed lower $\mathrm{pH}$ values and higher calcium content for the pot experiment at $15^{\circ}$ Celsius (Figure 5).
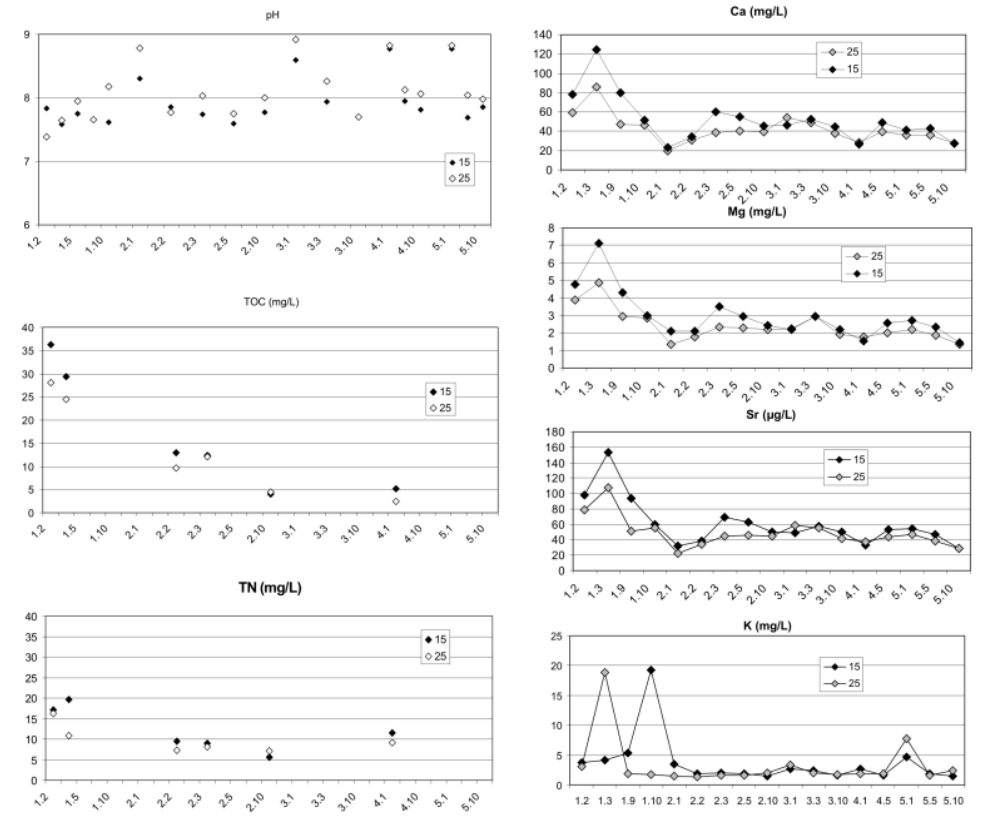

Figure 5 - Chemical and physical parameters measured in the infiltrates from the pot experiments. $X$ axis represents five years of the simulated rainfall; hence the number in the decimal digit is the number of rain event for each year.

Considering that chemical species such as $\mathrm{Ca}$ and $\mathrm{Sr}$ in the infiltrates were originated from dissolution of calcite and dolomite, higher dissolution was observed in the pot experiments at temperatures of $15^{\circ}$ Celsius. Higher concentrations were observed also for $\mathrm{Mg}$ at temperatures of $15^{\circ}$ Celsius compared to $25^{\circ}$ Celsius. Potassium was approximately identical to both temperatures, mainly because potassium originated from ion exchange reactions rather than dissolution reactions. The higher degree of calcium leaching in the pot experiments at $15^{\circ}$ Celsius (compared to that at $25^{\circ}$ Celsius) is due to higher organic content in the infiltrates which lower the soil solution $\mathrm{pH}$ (Figure 5). The high activity of $\mathrm{H}^{+}$was balanced by calcite dissolution either from the soil or the uncovered limestone surface. The chemical conditions and reactions at $15^{\circ}$ Celsius increase the calcite dissolution which, in turn, increased the carbonates. Thus the lower REE-Y sorption at limestone surface at $15^{\circ}$ Celsius was probably related to the mineralization of organic matter from soil microorganisms. The latter has a two-fold effect: a) lowering of the $\mathrm{pH}$ in the soil solution which may facilitate the desorption of REE-Y from clays, oxides and organic host sites and $b$ ) the 
dissolution of calcite in the limestone with rapid increases in the $\mathrm{pH}$ and sorption of the REE-Y on the limestone surface.

\subsection{Kinetic and Isotherm Experiments}

The \% of the REE removal in the sorption isotherms was $98-99 \%, 96-99 \% 97-99 \%$ for Ce, Eu and $\mathrm{Yb}$, respectively. No plateau was reached in the sorption test and the calcite capacity for REE sorption is considered high. Moreover, the preferable sorption of LREE has been observed mainly in sorption onto metal oxides (Koeppankastrop et al., 1991) and it has been attributed to stronger complexation of HREE, with carbonate anions which hold HREE in solution. There is a controversy whether the REE are strongly bound with carbonates and dicarbonates, or whether there is a strong effect of the ionic radii among the competitive cations in the case of sorption reactions (Coppin et al., 2002). In our case, the competitive cation was $\mathrm{Ca}^{2+}$. Comparing the calcium content in solution between the kinetic test and the isotherm test we record higher calcium concentration (by up to 1 order of magnitude) in the kinetic experiment compared to the isotherm experiment. This occurred because the kinetic test reached equilibrium without correcting the solution $\mathrm{pH}$, whereas in the isotherm test the $\mathrm{pH}$ was corrected (Figure 6). The lack of $\mathrm{pH}$ adjustment in the kinetic test increased the calcite dissolution after the addition of the REE standard solution (very acidic solution), whereas in the isotherm tests Ca precipitated due to the addition of $\mathrm{NaOH}$. The higher ionic strength in the kinetic test had no effect on the fast sorption of $\mathrm{Ce}$ and $\mathrm{Eu}$. The final sorption was $17 \%$ higher in the kinetic test, with higher ionic strength (ca. $\mathrm{I}=1.2$ ) than that recorded in the isotherm test of low ionic strength (ca. $\mathrm{I}=0.2$ ) Thus, ionic size effect in high ionic strength solution has no significant effects in the REE sorption. Moreover, the calcite dissolution in the kinetic test appears to have inevitably increased the $\mathrm{CO}_{3}{ }^{2-}$ as it probably created complexes with REE.
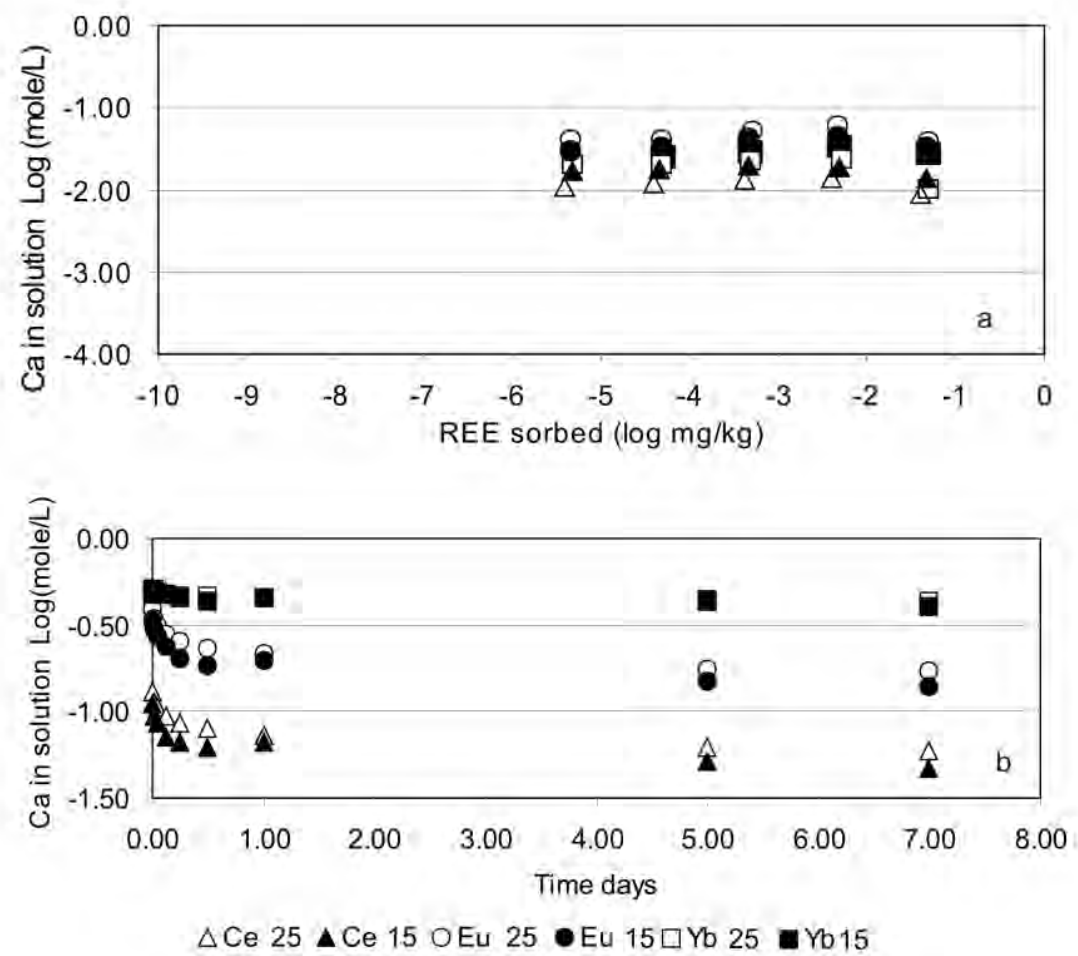

Figure 6 - The calcite content in the (a) isotherm and (b) kinetic experiments.

XLVII. No $2-849$ 
The kinetic test shows that the maximum REE sorption for all ionic radii species is attained after 24 hours; this is considered to be a fast reaction. The inferred high concentration of $\mathrm{CO}_{3}{ }^{2-}$ in the kinetic has not impeded the fast REE sorption in calcite. Fast REE sorption was also observed in sand by Tang and Johannesson (2005a). The same authors observed a slight decrease in the REE sorption after $12 \mathrm{~h}$; that was attributed to limited dissolution of the sorbent solid phases. In our experimental set up the slight decrease in the REE sorption is observed after the $5^{\text {th }}$ day. The fast sorption rate is mainly attained by a physisorption (adsorption) reaction compared to chemisortpion (absorption). The remark effect in $\mathrm{pH}$ experiment was the lower sorption rate for $\mathrm{Yb}$ compared to the remaining REE during the first day. The slower sorption rate for $\mathrm{Yb}$ may be attributed to the high affinity of $\mathrm{Yb}$ to create carbonate complexes which hold it in solution at least for the first 24 hours. Hence, we infer that due to the high dissolution of calcite in our batch experiments, the REE forms complexes with carbonates. Thus, the sorption of the REE on the calcite surface should occur in the form of $\mathrm{REECO}_{3}{ }^{+}, \mathrm{REEHCO}_{3}{ }^{2+}$.

\section{Conclusions}

The fast sorption of the REE-Y was evident both in pot experiments and kinetic tests. Due to the high calcite dissolution in our tests, we inferred that the REE were bound in carbonates and bicarbonates, which were sorbed onto the calcite surface. The mechanism of REE-Y enrichment in the limestone involved the three successive steps of: a) REE-Y release from the soil as a result of the $\mathrm{pH}$ reduction due to bioturbation; b) sorption on the limestone surface due to calcite dissolution which increased the $\mathrm{pH}$ and $\mathrm{c}$ ) enhancement in the REE-Y sorption. Further studies will focus on the nature of the sorption and the associated oxidation states of REE; however here we propose a physisorption, which progressively changes to inner sphere complexes, as a plausible mechanism for the inclusion of the REE-Y within the limestone surface.

\section{Acknowledgments}

This work was accomplished with the financial support of John S. Latsis Public Benefit Foundation. We sincerely thank the chemist Saru Maria-Liliana for the REE-Y measurements with ICP-MS and the Laboratory of Hydrogeochemical Engineering and Remediation of Soils for hosting us.

\section{References}

Carcaillet J., Manighetti I., Chauvel C., Schlagenhauf A. and Nicole J.M. 2008. Identifying past earthquakes on an active normal fault (Magnola, Italy) from the chemical analysis of its exhumed carbonate fault plane, Earth Planet. Sc. Lett., 271, 145-158.

Coppin F., Berger G., Bauer A., Castet S. and Loubet M. 2002. Sorption of lanthanides on smectite and kaolinite, Chem. Geol., 182, 57-68.

Dia A., Gruau G., Olivié-Lauquet G., Riou C., Molénat J. and Curmi P. 2000. The distribution of rare earth elements in groundwater: Assesing the role of source-rock composition, redox changes and colloidal particles, Geochim. Cosmochim. Ac., 64, 4131-4151.

Godelitsas A., Astilleros J.M., Hallam K., Harissopoulos S. and Putnis A. 2003. Interaction of calcium carbonates with lead in aqueous solutions, Environ. Sci.Technol., 37, 3351-3360.

Komnitsas K., Bartzas G. and Paspaliaris I. 2004. Efficiency of limestone and red mud barriers: laboratory column studies, Miner. Eng., 17, 183-194.

Koeppankastrop D., DeCarlo E.H. and Roth M. 1991. Amethod of investigate the interaction of rare earth elements in aqueous solution with metal oxides, J. Radioanal. Nucl. Ch., 152, 337-346.

Laveuf C. and Cornu S. 2009. A review on the potentiality of Rare Earth Elements to trace pedogenetic processes, Geoderma, 154, 1-12.

XLVII. No 2 - 850 
Manighetti I., Boucher E., Chauvel A., Schlagenhauf A. and Benedetti L. 2010. Rare earth elements record past earthquakes on exhumed limestone fault planes, Terra Nova, 22, 477482.

Mouslopoulou V., Moraetis D. and Fassoulas C. 2011. Identifying past earthquakes on carbonate faults: advances and limitations of the Rare Earth Element method based on analysis of the Spili Fault, Crete, Greece, Earth Planet Sc. Lett., 309, 45-55.

Palumbo L., Benedetti L., Bourles D., Cinque A. and Finkel R. 2004. Slip history of the Magnola fault (Apennines, Central Italy) from $36 \mathrm{Cl}$ surface exposure dating: evidence for strong earthquakes over the Holocene, Earth Planet. Sc. Lett., 225,163-176.

Patino L.C., Velbel M.A., Price J.R. and Wade J.A. 2003. Trace element mobility during spheroidal weathering of basalts and andesites in Hawaii and Guatemala, Chem. Geol., 202 (3-4), 343-364.

Papadopoulos P. and Rowell D.L. 1988. The reactions of cadmium carbonate surfaces, J. Soil Sci., 39, 23-36.

Roy P.D., Caballero M., Lozano S., Morton O., Lozano R., Jonathan M.P., Sánchez J.L. and Macías M.C. 2012. Provance of sediments deposited at paleolake San Felipe, western Sonora Desert: Implications to regimes of summer and winter precipitation during last $50 \mathrm{cal} \mathrm{kyr}$ BP, J. Arid Environ., 81, 47-58.

Samara C., Tsitouridou R. and Balafoutis Ch. 1992. Chemical composition of rain in Thessaloniki, Greece in relation to meteorological conditions, Atm. En., 26B, 359-367.

Sdiri A., Higashi T., Jamoussi F. and Bouaziz S. 2012. Effects of impurities on the removal of heavy metals by natural limestones in aqueous systems, J. Environ. Manage., 93, 245-253.

Shields G. and Stille P. 2001. Diagenetic constrains on the use of cerium anomalies as paleoseawater redox proxies: an isotopic and REE study of Cambrian phosphorites, Chem. Geol., 175, 29-48.

Tang, J., Johannesson, K.H., 2005a. Adsorption of rare earth elements onto Carrizo sand:experimental investigations and modeling with surface complexation. Geochim. Cosmochim. Ac., 5269, 5247-5261.

Zachara J.M., Kittrick J.A., Harsh J.B., 1988, The mechanism of $\mathrm{Zn}^{2+}$ adsorption on calcite. Geochim. Cosmochim. Ac., 52, 2281-2291. 